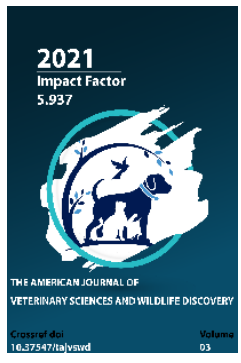

Copyright: Original content from this work may be used under the terms of the creative commons attributes 4.0 licence.

\section{Diagnosing Disease Of Cow Mastitis And Method Of Using Diffusion-Precipitation Reaction In Agar Gel}

\author{
Adham Khayrullayevich Bazarov \\ Assistant, Samarkand Institute Of Veterinary Medicine, Uzbekistan \\ Ozodbek Olimjon Ogli Sobirov \\ Student, Samarkand Institute Of Veterinary Medicine, Uzbekistan
}

\title{
ABSTRACT
}

The microbial factor is essential in the etiology of mastitis. In this regard, bacteriological diagnostics is one of the decisive moments in the recognition and differentiation of pathological conditions of the mammary gland.

However, it takes a lot of time to make a diagnosis using general methods, special culture media and reagents.

\section{KEYWORDS}

Mastitis, staphylococcus, streptococcus, agar, gel, modification, antitoxic, toxin, antigen, precipitate, stroke, plasma, koagulaza, hemolysis, DNK - asa, serologic.

\section{INTRODUCTION}

The role of microorganisms in the etiology of mastitis is important, and bacteriological diagnosis is one of the decisive factors in the pathological process in the mammary gland and its comparison.
Diagnosis with commonly used methods requires a certain amount of time, special nutrient media, and reagents to separate the pure culture from the milk and differentiate it. 


\section{MATERIAL AND METHODS}

The aim of our study was to save time in the process of improving bacteriological diagnostics, to isolate the pathogen, to determine its pathogenicity, not to reduce the pathogenicity of the pathogen used in previously available methods.

The main focus is on staphylococci and streptococci, which are the main causative agents of mastitis, and in our investigations we focused on the diffuse precipitation reaction in agar. We performed the reaction according to the Oudin and Ouxterloni method.

Such a choice is based on a rapid diagnosis of infectious diseases, based on the literature.

On the other hand, it is important in the diagnosis of mastitis. We modified the Sadjiyama, Bergdola, and Dhaka methods in diagnosing mastitis. Pathogenic staphylococci present in milk can be found in mastitis and do not require isolation of pure culture.

This involves inoculating the sample with a mixture of milk and antitoxic whey.

The pathogenicity of staphylococci can be determined by the production of a toxin (antigen).

Staphylococci react with antitoxic serum to form a precipitate line.

\section{The following elements were reworked in the reaction modification:}

1) Method of sowing a milk sample

2) The amount of sowing

3) Interval of sowing line with antitoxic staphylococcal serum, staphylococcus.

\section{RESULTS OF THE RESEARCH}

The results of the study showed that the sowing of milk is carried out in a straight line or with a bar length of $2-3 \mathrm{~cm}$ in the amount of $0.01 \mathrm{~cm} 3$, the distance from the pit to the whey is $0.8-1 \mathrm{~cm}$.

During the inspection, 151 milk samples from healthy and mastitis-infected animals were examined, of which 58 samples were isolated from staphylococcal cultures.

Toxicity was detected in 58\% of isolated cultures even when the DPR method was compared with the classical method. The results obtained are very consistent with plasmocoagulase and hemolysis, DNAmourning reactions, which came close to 61.65.66\%. In addition, the examination time was 3-4 days, while the DPR reaction was 2 days.

The sensitivity of the method was 10 microbial bodies per $1 \mathrm{~cm} 3$.

DPR is aimed at bacteriological diagnosis and serological types of mastitis caused by streptococci. The Kunter method caught our attention from pre-existing modifications. Its implementation is very convenient and easy, the results are clear, it is convenient to put the precipitation lines, $\mathrm{NaCl}$ was added to Difko agar and the spacing of the pits was 4-6 mm.

In parallel, 25 isolated cultures were examined based on Lansfield's precipitation reaction. We used polysaccharide $C$ as the antigen of the reaction.

We prepared the antigen for the Lensfield reaction in an acidic manner. For the DPR reaction, the antigen was prepared by Kunter's express method by precipitation of a culture of staphylococci in a saline solution, autoclaved, and precipitated. 
The results of the study showed that the antigen prepared for DPR does not lag behind the antigen prepared for the classical precipitation reaction in terms of its sensitivity and specificity, i.e., the antigen obtained by extraction.

\section{CONCLUSION}

Keeping in mind the classical method of precipitation reaction, the simplicity and ease of placement of the DPR reaction are taken into account. At the same time, compared with previous reactions, the reagents showed a 6-fold decrease in the consumption of antistreptococcal serum.

Thus, the introduction of a diffuse precipitation reaction in the gel reduces the time of diagnosis of mastitis and avoids the use of expensive reagents. Twenty-five streptococcal cultures reacted with specific serum with 24 (96\%) Lancefield-prepared antigen, and with Kunter-prepared antigen (99\%).

\section{REFERENCES}

1. V. I. Mutovin "Fight against cow mastitis". Ed. agricultural literature 1963. P-56-97.

2. Theses of reports of the scientific and technical conference "Problems, improving the quality of milk and prevention of mastitis in cows". VNIIS. Moscow 1969.

3. Bessarabov B. F. "Infectious diseases of animals". M. Kolos 2007 pp. 127-132.

4. Khoshimov, N. N., \& Nasirov, K. E. (2017). Action of Cytisinum on the Transport Mediators and Calcium Channel of Glutamatergic Neurotransmitter Systems of the
NMDA Receptor. European Journal of Medicine, (5-2), 56-63.

5. Stege, H., Bager, F., Jacobsen, E., \& Thougaard, A. (2003). VETSTAT-the Danish system for surveillance of the veterinary use of drugs for production animals. Preventive veterinary medicine, 57(3), 105-115.

6. Khoshimov, N. N., Kabil, N. E., \& Eshbakova, K. A. (2015). Research Influence Biological Active Agents in the Course of Regulation of Functional Activity of Platelets and System of a Haemostasis. European Journal of Medicine, (2), 88-93.

7. Eguchi, K., Nagase, H., Ozawa, M., Endoh, Y. S., Goto, K., Hirata, K., ... \& Yoshimura, H. (2004). Evaluation of antimicrobial agents for veterinary use in the ecotoxicity test using microalgae. Chemosphere, 57(11), 1733-1738.

8. Raimova, G. M., \& Khoshimov, N. N. (2016). Studying anticoagulant property of the GLAS of in vitro in system of a hemostasis.

9. Khoshimov, N. N., Nasirov, K. E., Raimova, G. M., Musaeva, M. K., Azizov, V. G., Murodov, S. S., ... \& Badirdinov, B. R. (2021). Study Of The Effect of Polysaccharides On Hemostasis. The American Journal of Medical Sciences and Pharmaceutical Research, 3(01), 131-138.

10. Spreng, M., Deleforge, J., Thomas, V., Boisrame, B., \& Drugeon, H. (1995). Antibacterial activity of marbofloxacin. A new fluoroquinolone for veterinary use against canine and feline isolates. Journal of Veterinary Pharmacology and Therapeutics, 18(4), 284-289.

11. Khoshimov, N. N., \& Nasirov, K. E. (2017). Action of Cytisinum on the 
Transport Mediators and Calcium

Channel of Glutamatergic

Neurotransmitter Systems of the

NMDA Receptor. European Journal of

Medicine, (5-2), 56-63.

12. Raimova, G. M., \& Khoshimov, N. N. (2016). Studying anticoagulant property of the GLAS of in vitro in system of a hemostasis.

13. Songa, E. B., \& Hamers, R. (1988, September). A card agglutination test (CATT) for veterinary use based on an early VAT RoTat $1 / 2$ of Trypanosoma evansi. In Annales de la Société belge de médecine tropicale (Vol. 68, No. 3, pp. 233-240).

14. Rossoff, I. S. (1975). Handbook of veterinary drugs. A compendium for research and clinical use. Springer Publishing Co..

15. Raimova, G. M., \& Khoshimov, N. N. (2016). Studying anticoagulant property of the GLAS of in vitro in system of a hemostasis. 